\title{
Designing and Validating a New Asian Family Scale
}

\author{
Musa $\mathrm{R}^{\mathrm{a}}$, Mat Aris $M \mathrm{~A}^{\mathrm{b}}$, Draman $\mathrm{S}^{\mathrm{b}}$, Abdullah $\mathrm{K}^{\mathrm{a}}$, Bujang $\mathrm{MA}^{\mathrm{c}}$ \\ aDepartment of Psychiatry, Kulliyyah of Medicine, International Islamic University Malaysia, Jalan Hospital, \\ 25150 Kuantan, Pahang. \\ bDepartment of Family Medicine, Kulliyyah of Medicine, International Islamic University Malaysia, Indera \\ Mahkota, 25200 Kuantan, Pahang. \\ 'Biostatistics Department, Clinical Research Centre, Kuala Lumpur, Malaysia.
}

\section{ABSTRACT}

Introduction: All available family scales are designed for western countries and there is no validated family scale which is specifically devised for Asian population. The difference in culture and family values warrants the formulation of a specific Asian family scale to cater the regional needs. The objectives are to devise and validate a new family scale and eventually to validate it for Malaysian population. Method: The development of the questionnaire can be divided into 5 stages; identifying the domains of Asian family values, items identification for each domain and language review, pretest the pre-final version, pilot study and validation. Respondents were recruited from different ethnic groups and cultural backgrounds to represent the Malaysian population. They were selected by using stratified quota sampling from various health centres in the district of Kuantan, Malaysia. Results: A total of 588 participants enrolled in the validation stage with various ethnic backgrounds. Bartlet's KMO value is 0.93 . From 43 items, $67 \%$ had good factor loading $(>0.4)$ and 13 items were finally dropped. Total Cronbach's alpha values of 0.9 with 5 domains were identified by using exploratory factor analysis. There are 6 items in each domain. Conclusion: This new scale has good psychometric properties and it is a valid family scale for Malaysians. Further psychometric evaluation will further enhance the evidence for other populations in Asia.

KEYWORDS: Asian; family scale; validation; reliability; psychometric properties; instrumental survey study.

\section{INTRODUCTION}

In order to understand the increasing number of social ills, it is important for us to have a locally validated questionnaire to gauge the dimension of Malaysia or Asian families. This issue is particularly crucial when we focus on social ills related to children and family. Areas such as social science, human psychology, child and woman psychiatry would certainly benefit by having a validated and a reliable instrument which enables us to explore family dynamics.

Across the globe, there are a handful of questionnaires such as Family Environmental Scale (FES), Family Assessment Measure (FAM) and Family Adaptability and Cohesion Evaluation Scale II which are designed to explore family environment. Among these questionnaires, FES is the most comprehensive and widely used. ${ }^{1,2}, 3$ Translating an existing scale and eventually validating it would be much more convenient

Corresponding author:

Prof. Dr. Ramli Musa

Department of Psychiatry,

Kulliyah of Medicine, International Islamic

University Malaysia,

Jalan Hospital, 25150 Kuantan, Pahang, Malaysia

Tel: $+6091-5716400$

$H / P:+6017-8222243$

Fax: $+609-5133615$

Email: ramlidr@yahoo.com / drramli@iium.edu.my but unfortunately not all questionnaires are applicable to this adopting method. The idea of inventing a new scale is necessitated because of the poor outcomes of previous research project "Cross-cultural Adaptation and Validation of Malaysian language of the Family Environment Scale (FES) Questionnaire" which was funded by Ministry of Health Malaysia. The result of this project shows that direct translation and subsequent adopting of western questionnaire is not always feasible. ${ }^{4}$ There are substantial differences in various family domains and concepts between western and Asian cultures. Although the translation of FES was done based on the stipulated and strict procedures, the validation results of Malay version of FES yielded poor factor analyses. The poor results were not caused by error of translation but it was due to core element that western and Asian family concepts are different. In a western family for example, the ability to express unhappiness among family members, is viewed as acceptable. However the openness to vent out unhappiness is viewed as a disharmony in an Asian family.

The objectives of this study are to construct a new family scale and to determine its reliability and construct validity among Malaysian population. This study has strong ramifications on the nurturing research path related to family environment. 


\section{MATERIALS \& METHODS}

All the subjects were recruited by stratified random sampling. Stratification was adopted to ensure the ethnic distribution of the sample would represent the actual Malaysian population. The inclusion criteria are literate in Malaysian language, able to give written consent and aged between 12 to 65 years. The study was approved by the internal review board of
International Islamic University Malaysia ethics committee. In the process of validation of a new scale in Malaysia, we need to take into consideration that the Malaysian population has 3 major ethnic groups with different mother tongues.

The development of the questionnaire can be divided into 5 stages and it is summarized by the flowchart;

Figure 1: Workflow of designing a new family scale.

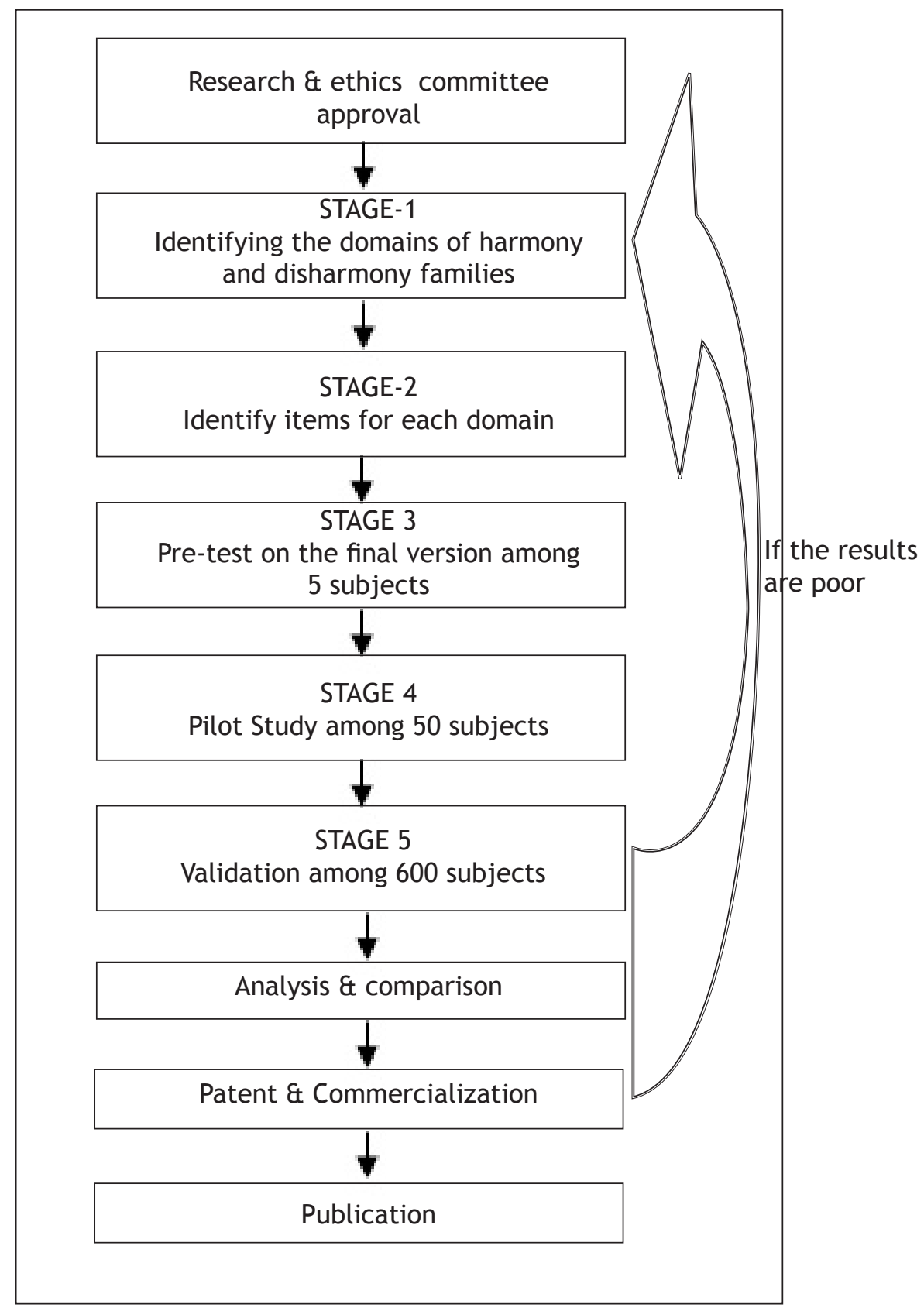

In stage 1, we identified a few areas of subjects' concern about the aspects of harmony and disharmony in families. Based on stage 2, among the proposed domains were togetherness/family cohesion, expression and communication, common activities, family dynamic/ structure, ability to overcome challenges, religious affiliation and cultural belief, interpersonal and social skills and individual rights.
After the language review, the next stage (stage 3) was focusing on pre-test of pre-final product. The aim of this stage was to look at any ambiguous terms and sentence structures of pre-final questionnaire before researchers embark on a pilot study. The pretest was to ensure that the sentence in each item is well understood and non-ambiguous in nature. The pre-test was done on small group of volunteers with different academic and racial backgrounds. Sentence 
by sentence review to find out whether the sentences and words used are jargon-free.

Pilot study in stage 4, was aimed to test the final version of Asian family scale before full scale of validation recruitment. The pilot study was done on attendees of primary health clinics by using stratified quota sampling. In stage 5 (validation stage), a total of 600 subjects were recruited with different ethnic groups and cultural backgrounds to represent Malaysian population. The stratification of the subjects was based on the ethnicity. This is to ensure the results obtained in this study could be generalized to the Malaysian population. The subjects were recruited from various health centres in the district of Kuantan, Malaysia. The figure of 600 subjects was obtained based on simple estimation of 10 subjects per item.

\section{RESULTS}

Table 1: Socio-demographic data of the respondents

\begin{tabular}{llll}
\hline Variable & $\begin{array}{l}\mathbf{N} \\
(\mathrm{N}=175)\end{array}$ & $\begin{array}{l}\text { Percentage } \\
(\%)\end{array}$ & Total \\
\hline Gender & & & \\
- Male & 245 & 42.2 & 578 \\
- Female & 333 & 57.4 & \\
Age (years) & & & 578 \\
- Mean & 29.7 & & \\
- Median & 29 & & \\
- Range & $13-61$ & & 580 \\
Ethnic & & & \\
- Malay & 474 & 81.7 & \\
- Chinese & 51 & 8.8 & \\
- Indian & 52 & 9.0 & \\
- Others & 3 & 0.5 & \\
Education & & & \\
- Primary school & 44 & 7.6 & \\
- Secondary school & 267 & 46.0 & \\
- Tertiary education & 254 & 43.8 & \\
- Not schooling & 11 & 1.9 & \\
\hline
\end{tabular}

Based on table 1, from a total of 600 selected respondents, 588 agreed to participate and 8 were excluded. From 580 respondents, $81.7 \%$ were Malays, $8.8 \%$ were Chinese and $9.5 \%$ were other races. Of these participants, $57 \%$ were females and $43 \%$ obtained secondary education. The age range is between 13 to 61 years. This indicates as early as 13 year-old could understand the scale. The sample is adequate as the Kaiser-Meyer-Olkin values are 0.93 which is very good.

Based on analysis of 43 initial items, most of the items had good Cronbach's alpha values. The lowest Cronbach's value of initial 43 items is 0.69 . Based on exploratory factor analysis with Varimax rotation on initial 43 items, we decided to omit 13 items which had poor factor loadings, reason of redundancy, poor outcome based on feedbacks during pre-test and other statistical analyses. Next analysis is based on 30 finalized items.
Based on the table 2, analysis with Varimax rotation without force, we obtained very good and nicely identified 30 items with 5 domains with 6 items in each domain. The 30 analyzed items were having good factor loadings as displayed in table 2. The factor loading are nicely fit into their respective domains. The 5 identified domains are namely Togetherness/ Harmony (factor 1), Expression (factor 2), Relationship \& Family dynamic (factor 3), Conflict (factor 4) and Religiosity \& Traditional Practice (factor 5). Overall Cronbach's alpha is very good $(0.90)$. When we analyzed Cronbach's alpha for each one of 5 domains, we managed to get the values of $0.67,0.814,0.71$, 0.74 and 0.77 for factor $1,2,3,4$ and 5 respectively. 
Table 2: Factor loading of each item based on Exploratory Factor Analysis

\begin{tabular}{|c|c|c|c|c|c|c|}
\hline \multirow{2}{*}{ Items } & \multirow{2}{*}{$\begin{array}{l}\text { Cron- } \\
\text { bach's } \\
\text { alpha if } \\
\text { item } \\
\text { deleted }\end{array}$} & \multicolumn{5}{|c|}{ Component \& factor loadings } \\
\hline & & Factor 1 & Factor 2 & Factor 3 & Factor 4 & Factor 5 \\
\hline $\begin{array}{l}\text { 1._exercise and carry out activities } \\
\text { together }\end{array}$ & 0.71 & 0.65 & & & & \\
\hline $\begin{array}{l}\text { 2._frequently visit our close } \\
\text { relatives }\end{array}$ & 0.71 & 0.58 & & & & \\
\hline $\begin{array}{l}\text { 3. _do the house chores together during } \\
\text { weekends }\end{array}$ & 0.71 & 0.70 & & & & \\
\hline $\begin{array}{l}\text { 4._usually watch movies with family } \\
\text { members }\end{array}$ & 0.70 & 0.68 & & & & \\
\hline $\begin{array}{l}\text { 5. _usually discuss whenever we have } \\
\text { problems }\end{array}$ & 0.71 & 0.61 & & & & \\
\hline $\begin{array}{l}\text { 6._smile because there is harmony in our } \\
\text { family }\end{array}$ & 0.71 & 0.34 & & 0.46 & & \\
\hline 7. _fight over small or trivial matters & 0.70 & & 0.62 & & & \\
\hline $\begin{array}{l}\text { 8._prefer keep our own problems to } \\
\text { ourselves }\end{array}$ & 0.69 & & 0.76 & & & \\
\hline 9. _keep our feelings to ourselves & 0.69 & & 0.74 & & & \\
\hline 10. _my parents do not understand me & 0.70 & & 0.74 & & & \\
\hline $\begin{array}{l}\text { 11._difficult for me to understand my } \\
\text { family }\end{array}$ & 0.70 & & 0.69 & & & \\
\hline 12. _they usually controls me & 0.70 & & 0.61 & & & \\
\hline $\begin{array}{l}\text { 13. _express love through hugging and } \\
\text { kissing }\end{array}$ & 0.71 & 0.44 & & 0.37 & & \\
\hline 14. _help one another & 0.71 & & & 0.64 & & \\
\hline 15. _often receive praises for each other & 0.70 & & & 0.62 & & \\
\hline $\begin{array}{l}\text { 16. concerned the problems of each } \\
\text { family member }\end{array}$ & 0.71 & & & 0.67 & & \\
\hline 17._respect our elders & 0.71 & & & 0.64 & & \\
\hline $\begin{array}{l}\text { 18. _family member fulfils his/her } \\
\text { responsibilities }\end{array}$ & 0.70 & & & 0.65 & & \\
\hline 19._are usually self-centred or selfish & 0.70 & & & & 0.53 & 0.35 \\
\hline 20. _solve problems on our own & 0.69 & & & & 0.57 & 0.44 \\
\hline $\begin{array}{l}\text { 21. family members are isolated or isolate } \\
\text { themselves }\end{array}$ & 0.69 & & & & 0.65 & 0.33 \\
\hline $\begin{array}{l}\text { 22. _ irresponsible and cause } \\
\text { inconvenience to others }\end{array}$ & 0.70 & & & & 0.69 & \\
\hline 23. _often raise our voices when discussing & 0.69 & & & & 0.67 & 0.34 \\
\hline $\begin{array}{l}\text { 24. _retaliate when they are being } \\
\text { reminded by others }\end{array}$ & 0.70 & & & & 0.75 & \\
\hline $\begin{array}{l}\text { 25. knock the door and ask for permission } \\
\text { before entering.. }\end{array}$ & 0.70 & & & & & 0.64 \\
\hline $\begin{array}{l}\text { 26. _often engage ourselves in spiritual } \\
\text { activities }\end{array}$ & 0.71 & & & & & 0.77 \\
\hline $\begin{array}{l}\text { 27. celebrate festive seasons (Chinese New } \\
\text { Year, etc) together }\end{array}$ & 0.71 & & & & & 0.64 \\
\hline $\begin{array}{l}\text { 28. often discuss religious matters } \\
\text { together }\end{array}$ & 0.71 & & & & & 0.61 \\
\hline $\begin{array}{l}\text { 29. _taught to respect other religious \& } \\
\text { cultural belief }\end{array}$ & 0.70 & & & & & 0.70 \\
\hline 30. _always keep things tidy and organized & 0.71 & & & & & 0.69 \\
\hline
\end{tabular}

Extraction Method: Principal Component Analysis. Rotation Method: Varimax with Kaiser Normalization. 


\section{DISCUSSION}

It is evident that there have been rapid economical, cultural and technological developments in the past two decades. Socioeconomic developments are known to impact family dynamics across the globe. Asian communities are also not spared by the rapid global development. Hence, we could expect some diversity and changes in Asian family values. However literatures indicate that Asian families are still strongly retain certain unique values. ${ }^{5}$

Research in the field of family study in Asia is facing a setback as there is no validated instrument to explore the family environment. The intensifying social related problems such as illegal racing, substance misuses, conduct disorder, physical and sexual abuses, indicate that the exploration of family environment is essential.

Asian families are different in various aspects. Asian family structure is very much influenced by the religious instillation in which embraced by that community. It has been documented that individual family members may take the approach of passive, indifferent and indecisive in order to avoid conflict. ${ }^{5}$ Asian families remain stable despite serious internal conflicts. The prominent factors of resilience and the readiness to sacrifice are generally attributed to strong religious practices and traditions. People from rural areas are relatively more close to God and feel religiously stronger. ${ }^{6}$

This study managed to devise and validate a new family instrument for Asian countries namely the Asian Family Characteristics Scale (AFCS). Five domains were constructed out of 30 items namely Togetherness/ Harmony (Factor 1), Expression (Factor 2), Relationship \& Family dynamic (Factor 3), Conflict (Factor 4) and Religiosity \& Traditional Practice (Factor 5). These five domains represent five important areas in measuring family functioning.

Based on our analysis, items related to basic concept of Asian family values such as traditional practice, religious rituals, religious celebration yielded high factor loadings. Other questionnaires such as FES and FAM emphasize certain similar domains such as Cohesion, Togetherness and Conflict.

We identified a few differences of this scale as compared to other family scales. This scale is specifically designed to cater the need for Malaysian multi-ethnic population. Since religion is an important element in Asian communities, we included religious and traditional practice in the scale. Based on the results, the items related to traditional and religious practices displayed better factor loadings. This new scale also focuses on extended family function. In Asian population, extended family still plays a major role as an important source of family support. Each family member must understand their status in family hierarchy. Hence the value of respecting the elders is viewed as an important aspect. ${ }^{5}$ FES has 9 domains, FAM has 6 domains and Family Adaptability and Cohesion Evaluation Scale II has 2 domains namely Family Cohesion and Family Adaptability. We also emphasis in this scale the local concepts of Malaysian family. This includes common leisure activities and spending time together. This aspect is pertinent to Asian families. Studies in the past showed that there is a positive relationship between joint family leisure activities and family life satisfaction. ${ }^{7,8}$

In this new scale, the authors decided to incorporate 4-scoring Likert scale. As compared to FES, it has only dichotomous scoring (yes or no). In this newly invented scale, we decided to have bipolar multi-stage scoring. Based on outcomes of translation of the FES project, we found that dichotomous scale would have optimum value on factor loadings. Dichotomizing a continuous variable would lead to loss of efficacy of the instrument and a reduction in its correlation with other measures. ${ }^{9}$

A small weakness of this study, relates to the selection of subjects based on random sampling, hence there is an overrepresentation of Malays as compared to Chinese.$^{10}$ It is a common observation that Chinese are less likely to be interested to participate in studies. ${ }^{11,12}$ Although our sample might not ideally representative of Malaysian population with respect to racial distribution, findings in this study could be generalized to Malaysian population due to relatively large sample size of this study.

With good Cronbach's alpha values (internal consistency) and good factor loadings by using Explanatory Factor Analysis, we believe this is good preliminary outcomes. However, further exploration on other populations in other part of Asia and more robust methodology such as criterion validity and confirmatory factor analysis would further enhance the evidence of its psychometric properties.

Conclusion; The new scale has good psychometric properties. The results of this study may act as an initial validation finding and further studies with more robust methodology are necessary for enhance the psychometric properties of this scale. We also intend to validate this scale in the future in other Asian countries with different languages and community backgrounds. Asian family values are different from western which require a special psychometric tool. This newly prepared scale looks set to serve research purposes well.

\section{REFERENCES}

1. Moos R, Moos B. Family Environment ScaleManual. 2nd ed. Palo Alto, CA: Consulting Psychologists Press, 1986.

2. Moos RH, Moos BS. Family Environment Scale Manual: Development, Applications, Research 3rd Ed. CA: Stanford University Medical Centers, 2002. 
3. Dawn MG, Jacob T. Factor structure within and across three family assessment procedures. J Fam Psycho 1993; 6:278-289.

4. Khairani O, Ramli M, Jamaiyah $\mathrm{H}$, Azimah NM, Adam B, Farihna MF. Reliability of Bahasa Malaysia Version of Family Environment Scale and Its Measurement Issues. ASEAN Journal of Psychiatry 2010; 11:44-55.

5. Philips W. Culturally Competent Practice, Understanding Asian Family Values. Journal of the National Resource Center for Special Needs Adoption, Spaulding for Children 1996; 10:1-2.

6. Yasuda T, Iwai N, Yi C, Xie G. Intergenerational coresidence in China, Japan, South Korea and Taiwan: Comparative analyses based on the East Asian Social Survey 2006. J Com Fam Stud 2011; 42:703-722.

7. Chatwood S, Bjerregaard P, Young TK. Global Health-A Circumpolar Perspective. Am J Public Health 2012; 102:1246-1249.

8. White MP, Dolan P. "Accounting for the Richness of Daily Activities". Psychol Sci 2009; 20:10001008.

9. David LS, Norman GR. Health Measurement Scales. 3rd ed. Oxford: Oxford Scholarship Online, 2009.

10. Department of Statistics Malaysia Characteristics of Household 2010. Kuala Lumpur Malaysia. 2010.

11. Ramli M, Jamaiyah $\mathrm{H}$, Azimah NM, Khairani O, Adam B. Cross-cultural Adaptation And Validation of the Malaysia Version of the Eating Disorder Examination Questionnaire (EDE-Q). Malaysian Journal of Psychiatry 2008; 17:55-63.

12. Ramli M, Salmiah MA, Nurul AM. Validation and psychometric properties of Bahasa Malaysia version of the Depression Anxiety and Stress Scales (DASS) among diabetic patients. Malaysian Journal of Psychiatry 2010; 18:40-45. 